\title{
LA ARTICULACIÓN DEL CONTROL PARLAMENTARIO SOBRE LOS ESPACIOS LIBRES DE CONTROL GUBERNAMENTAL: PARLAMENTO Y ADMINISTRACIONES INDEPENDIENTES*
}

\author{
CRISTINA PAUNER CHULVI \\ Profesora Titular de Derecho Constitucional \\ Universidad Jaume I de Castellón
}

SUMARIO

I. Introducción.

II. El Parlamento y las Administraciones independientes: la dificultad de articular un control parlamentario sobre el Ejecutivo en su concepción clásica.

III. La parlamentarización de los nombramientos de los órganos directivos de las Administraciones independientes.

IV. Los controles sobre las Administraciones independientes: las especificidades previstas en su control parlamentario 1 . La comparecencia previa del Ministro competente ante las Comisiones parlamentarias 2. El control parlamentario de conflictos de intereses: la Ley 5/2006, de 10 de abril, de regulación de los conflictos de intereses de los miembros del Gobierno y de los Altos Cargos de la Administración General del Estado 3. Otros mecanismos de control parlamentario.

* El presente trabajo de investigación se ha elaborado en el marco del proyecto I+D sobre "Las Administraciones independientes y su problemática en un Estado social y democrático de Derecho integrado en la Unión Europea" (Ref. MCT-CICYT BJU2003-08363) financiado por el Ministerio español de Ciencia y Tecnología y del proyecto de investigación sobre Parlamentos autonómicos (referencia BSO-2003-06386) financiado por el Plan Nacional de Investigación Científica, Desarrollo e Innovación Tecnológica 2000-2003 y los Fondos Europeos de Desarrollo Regional (FEDER). 


\section{INTRODUCCIÓN}

Uno de los pilares sobre los que se asienta el Estado democrático es el del sometimiento de toda la actividad pública a control y responsabilidad. La Constitución española de 1978 determina que los poderes públicos emanan del pueblo español (art. 1.2 CE) que se encuentra representado en las Cortes Generales (art. 66.1 CE) de donde nace el Ejecutivo (arts. 99 y $100 \mathrm{CE}$ ). En nuestro sistema parlamentario y como consecuencia de la relación de confianza que debe existir entre el Parlamento y el Ejecutivo, toda la acción del Gobierno queda sometida al control de las Cortes Generales según dicción del art. 66.2 CE. En la realización de esas funciones de dirección política que se encomiendan al Gobierno, la Administración juega un papel fundamental (art. 97 CE). Precisamente, gracias a la cadena de responsabilidades y al juego del principio de jerarquía, el Gobierno responde ante el Parlamento por esa labor de orientación y dirección de la Administración.

Sin embargo, la aparición hace algo más de dos décadas en España de ámbitos de gestión pública caracterizados por su neutralidad y dotados de un status de independencia respecto del poder gubernamental ha conllevado una especificidad en las manifestaciones de los instrumentos de control parlamentario y gubernamental. Estas instituciones hacen de la independencia frente a directrices político-gubernamentales la nota esencial de su régimen jurídico de ahí que reciban, entre otras, la denominación doctrinal de Administraciones independientes. Dentro de esta categoría cabría citar, en el ámbito estatal, al Banco de España (BE), el Consejo de Seguridad Nuclear (CSN), la Comisión Nacional de Energía (CNE), el Comité del Mercado de Telecomunicaciones (CMT), el Tribunal de Defensa de la Competencia (TDC), la Agencia de Protección de Datos (APD) y el Consejo Administrativo de la Corporación RTVE ${ }^{1}$.

Como apuntábamos, el fenómeno de las Administraciones independientes ni siquiera es relativamente novedoso entre nosotros ${ }^{2} \mathrm{y}$, al margen de numerosísimos estudios sobre instituciones concretas, excelentes monografías han abordado su análisis desde una perspectiva global y, por lo que a nosotros nos interesa, constitucional ${ }^{3}$.

Aunque el elenco de entes independientes y sus funciones es muy heterogéneo, la finalidad con la que aparecieron es la necesidad de garantizar la

1 A nivel autonómico, también se han creado algunas Administraciones independientes a las que aludiremos cuando presenten alguna especialidad de interés relacionada con el objeto de nuestra investigación.

2 La primera regulación de las Administraciones independientes en nuestro país puede datarse en 1980 con la publicación de la Ley 4/1980, de 10 de enero, de creación del Ente Público Radio Televisión Española y la Ley 15/1980, de 22 de abril, del Consejo de Seguridad Nuclear.

3 Especialmente, A. RALLO LOMBARTE: La constitucionalidad de las Administraciones independientes, Tecnos, Madrid, 2002; M. SALVADOR MARTÍNEZ: Autoridades independientes, Ariel, Barcelona, 2002. Entre los administrativistas, puede consultarse M. MAGIDE HERRERO: Límites constitucionales de las Administraciones independientes, INAP, Madrid, 2000 y A. BETANCOR RODRÍGUEZ: Las Administraciones independientes. Un reto para el Estado social y democrático de Derecho, Tecnos, Madrid, 1994. 
neutralidad en el ejercicio de determinadas funciones de garantía de derechos y libertades y/o para promocionar la eficacia en la gestión pública mediante la vigilancia sobre sectores económicos o sociales. Estas funciones vendrán a desarrollarse al margen de la influencia de los partidos políticos y, para ello, se confía en el "gobierno de los sabios", es decir, en organismos que, bajo la dirección de un grupo de expertos, aplican criterios técnicos y objetivos a la hora de decidir y cuya legitimidad se resolvería en base al saber y la imparcialidad de sus miembros. Es lo que ha venido a conocerse como "despolitización de lo público" ${ }^{4}$.

Desde el mismo momento de la aparición de estos organismos, fueron numerosas las objeciones que se plantearon desde el punto de vista de su compatibilidad con el texto constitucional: la quiebra del principio democrático, su configuración como un cuarto poder inadmisible en un Estado democrático de Derecho, la usurpación legislativa de la función directiva gubernamental sobre la Administración, la devaluación de la función gubernamental de dirección política o la infracción de la reserva constitucional de jurisdicción y del principio de exclusividad judicial'5.

Dentro de esta compleja problemática constitucional, nuestro objetivo es muy acotado: centrarnos en el análisis de los mecanismos de control parlamentario que se articulan en torno a estas Administraciones independientes. En general, la dirección de la Administración civil es un supuesto inicial para que el Gobierno pueda llevar a cabo sus actividades de dirección política y, si bien la Administración actúa con sometimiento a la ley y obligada por la objetividad e imparcialidad que de su actuación proclama el artículo $103 \mathrm{CE}$, dispone de un margen de apreciación que la propia ley le reconoce siéndole consustancial la discrecionalidad. Esta discrecionalidad u oportunidad administrativa queda, por la cláusula de dirección de la Administración del art. $97 \mathrm{CE}$, sometida a control político de forma que es el Gobierno quien se hace responsable ante el Parlamento y la opinión pública.

Esta construcción quiebra desde su base cuando nos ocupamos de las Administraciones independientes debido su alejamiento de la lógica política: en realidad, y debido a su configuración como tales, las Administraciones independientes no resultan sometidas al control por parte del Gobierno y éste, a su vez, no avala por una actividad que, en realidad, no queda bajo su responsabilidad. Sin embargo, nadie pone en duda el ejercicio de cierto grado de dirección política por parte de estas Administraciones. Como señala la doctrina, «la experiencia demuestra que, como consecuencia de la complejidad que van adquiriendo las sociedades actuales, la actividad de las agencias de expertos no es sólo gestión sin margen alguno de discrecionalidad, sino que estos organismos desarrollan actividades de verdadera dirección política ${ }^{6}$.

4 A. RALLO LOMBARTE: "Poderes neutrales exentos de control gubernamental: reflexiones constitucionales", Revista de las Cortes Generales, núm. 36, 1995, pág. 106.

5 Sobre estos y otros argumentos puede verse en profundidad A. RALLO LOMBARTE: La constitucionalidad de las Administraciones independientes..., págs. 159 a 210.

6 M. SALVADOR MARTÍNEZ: Autoridades independientes..., pág. 301. 
Por ello, se presenta un reto a superar que resume López Guerra cuando afirma que "la existencia de ámbitos exentos del control parlamentario directo o indirecto pugna con el carácter democrático del Estado en el que España se constituye (art. 1.1 CE) y, en consecuencia, no puede tolerarse, ${ }^{7}$ de modo que "no cabe en principio que poderes cuya actuación en cuanto no sea mera ejecución de las decisiones de otros no esté sujeta a control y exenta de responsabilidad. No cabe así un acción política o de gobierno incontrolada o irresponsable, lo que da lugar a la cuestión de cómo se efectúa ese control y cómo se exige esa responsabilidad ${ }^{8}$.

\section{EL PARLAMENTO Y LAS ADMINISTRACIONES INDEPENDIENTES: LA DIFICULTAD DE ARTICULAR UN CONTROL PARLAMENTARIO SOBRE EL EJECUTIVO EN SU CONCEPCIÓN CLÁSICA}

La ruptura del circuito de responsabilidades en el sistema parlamentario supone que, en relación con la actuación de las Administraciones independientes, no es posible articular un control del Parlamento sobre el Ejecutivo en su concepción más clásica. Un somero análisis de las leyes de creación de las Administraciones independientes evidencia que la relación que se establece entre éstas y el Gobierno no responde a las técnicas jurídicas que se emplean para establecer el vínculo de dependencia tradicional entre la Administración gubernativa y la Administración institucional.

Por lo que respecta a los instrumentos personales, la facultad de nombramiento y remoción de los integrantes de los órganos constituye, por excelencia, la clave del control efectivo por parte de la Administración gubernativa del funcionamiento de los organismos públicos. Por ello, las disposiciones que regulan los nombramientos de los integrantes de los órganos rectores de las Administraciones independientes tratan de protegerlos de hipotéticas presiones políticas que puedan menoscabar la teórica neutralidad de sus funciones disociando ambas facultades de forma que se imposibilite el libre cese por parte de los órganos que son competentes para la designación. Esta disociación afecta al Gobierno quien mantiene el poder de nombrar o designar los titulares de los órganos rectores de la mayoría de estos entes pero no la de cesarlos en otros muchos?.

7 L. LÓPEZ GUERRA: "La posición constitucional del Gobierno", en Gobierno y Administración en la Constitución, vol. I, IEF, Madrid, 1988, pág. 30. En el mismo sentido, A. RALLO LOMBARTE: «Poderes neutrales exentos de control gubernamental: Reflexiones constitucionales"..., pág. 110.

8 L. LÓPEZ GUERRA: "Consejo General del Poder Judicial y política de la Justicia", en La democracia constitucional. Estudios en homenaje al Profesor Francisco Rubio Llorente, Congreso de los Diputados, Tribunal Constitucional, Universidad Complutense de Madrid, Centro de Estudios Políticos y Constitucionales, Madrid, 2002, pág. 1018.

9 Sobre los procedimientos de designación, puede consultarse C. PAUNER CHULVI: La designación parlamentaria de cargos públicos, Congreso de los Diputados, Madrid, 2003. 
Así, las leyes de creación de las Administraciones independientes han atribuido al Gobierno la potestad de nombrar a sus órganos directivos con la salvedad de la Corporación RTVE. En relación con el BE su ley reguladora prevé que el Gobernador sea nombrado por el Rey a propuesta del Presidente del Gobierno. También los Consejeros no natos y el Subgobernador del BE son nombrados por el Gobierno; los primeros oído el Gobernador y el segundo, a propuesta del Gobernador ${ }^{10}$. La CMT está formada por un Consejo de nueve personas con un Presidente, un Vicepresidente y siete consejeros que serán nombrados por el Gobierno, mediante Real Decreto adoptado a propuesta conjunta de los Ministros de Economía y Ciencia y Tecnología ${ }^{11}$. También, el nombramiento gubernamental de los miembros de la CNE - Presidente y ocho vocales - recae sobre el Gobierno ${ }^{12}$. El Consejo de la CNMV está compuesto por un Presidente y un Vicepresidente, nombrados por el Gobierno a propuesta del Ministro de Economía, dos consejeros natos (el Director general del Tesoro y Política Financiera y el Subgobernador del Banco de España) y tres consejeros nombrados por el Ministro ${ }^{13}$. El nombramiento del Presidente y los ocho vocales del TDC es competencia del Gobierno a propuesta del Ministro de Economía. El Vicepresidente lo elige el propio Tribunal entre sus miembros ${ }^{14}$. El nombramiento del Director de la APD recae sobre el Gobierno, mediante Real Decreto, a propuesta del Ministro de Justicia de entre los miembros del Consejo Consultivo ${ }^{15}$. Por último, el supuesto de nombramiento del Presidente y los Consejeros de la CSN es también gubernamental ${ }^{16}$.

Son estas mismas leyes las que prevén que la remoción de sus puestos sólo podrá producirse por causas tasadas en las que distinguimos una serie de supuestos objetivos o ligados a la voluntad del sujeto cesante (fallecimiento, expiración del mandato, renuncia, incapacidad permanente, incompatibilidad sobrevenida, condena o procesamiento por delito doloso) y otro tipo de causas de ambigua formulación como la de "falta de diligencia o incumplimiento grave de las obligaciones del cargo" ${ }^{17}$.

10 Art. 24.1 de la Ley 13/1994, de 1 de junio, de Autonomía del Banco de España (LABE).

11 Art. 48 de la Ley 32/2003, de 3 de noviembre, General de Telecomunicaciones (LGT).

12 Disp. Adicional Undécima de la Ley 34/1998, de 7 de octubre, del Sector de Hidrocarburos (LSH).

13 Art. 17 de la Ley 24/1988, de 28 de julio, del Mercado de Valores (LMV).

14 Art. 21.1 y 4 de la Ley 16/1989, de 17 de julio, de Defensa de la Competencia (LDC).

15 Arts. 36 y 38 de la Ley Orgánica 15/1999, de 13 de diciembre, de Protección de Datos de carácter personal (LOPD).

16 Art. 5.2 de la Ley 15/1980, de 22 de abril, de Creación del Consejo de Seguridad Nuclear (LCSN).

17 Ejemplos hay, sin embargo, de Administraciones independientes en el ámbito autonómico en cuyas normas reguladoras no se ha incluido este supuesto de remoción: así, los miembros del Consejo Audiovisual de Cataluña y de Navarra sólo podrán cesar por expiración del mandato, renuncia, fallecimiento, incapacidad permanente, incompatibilidad sobrevenida, inhabilitación para el ejercicio de cargos públicos o condena en virtud de sentencia firme por delito doloso (art. 7 de la Ley $2 / 2000$, de 4 de mayo, del Consejo del Audiovisual de Cataluña y art. 24 de la Ley Foral 18/2001, de 5 de julio, que regula la actividad audiovisual de Navarra y crea el Consejo Audiovisual de Navarra). 
El reconocimiento de la potestad de cese en el cargo por "falta de diligencia o incumplimiento grave de las obligaciones" ha planteado la cuestión de ser un instrumento que permita alguna ocasión para un control de oportunidad del Gobierno. Ciertamente, existen previsiones de cese o separación del cargo para las que es suficiente el acuerdo del Gobierno a propuesta motivada del Ministro competente (Disp. Adic. 11.primero.5 LSH) o previa instrucción de expediente por el mismo (art. 48.8 LGT, art. 20.c LMV). Realmente este supuesto manifiesta la facultad de control gubernamental sobre el funcionamiento de estos órganos para evitar irregularidades particularmente graves y matiza la garantía de inamovilidad de los órganos directivos de las Administraciones independientes que deja de ser absoluta. No puede dejar de advertirse que esta facultad se precisa mediante la exigencia de algunos requisitos. En primer lugar, existen ciertas garantías procedimentales previstas por el ordenamiento que impedirían el intento de violentar la inamovilidad de los miembros de las Administraciones independientes como la exigencia legal de que al cese gubernamental le preceda un expediente motivado (art. 36.3 LOPD), la propuesta del propio órgano colegiado (art. 23.1 LDC), la intervención en el proceso del sujeto afectado (art. 25.4.d LABE) o la autorización o veto parlamentario para ejecutar tal decisión (art. 7.1 LCSN) y, en segundo término, se entiende que esta causa de cese está prevista pensando en una conducta gravemente irregular de alguno de los miembros de los órganos rectores mientras que la responsabilidad sobre mala gestión debería hacerse valer sobre el colegio en general o sobre su Presidente, en todo caso. En conclusión, según afirma la doctrina, se trata de diseñar "un freno a conductas gravemente irregulares de miembros concretos de los órganos rectores y no a enderezar una gestión conjunta del organismo que el Gobierno juzgue deficiente o inconveniente, ${ }^{18}$.

La capacidad de dirección sobre las Administraciones independientes también se neutraliza mediante una serie de elementos que concurren en las normativas legales de las Administraciones independientes.

Entre los elementos que pueden ayudar a suavizar la influencia del Ejecutivo en la elección, puede señalarse, en primer lugar, la asincronía de mandatos de los titulares de los órganos rectores de estas Administraciones con el del Gobierno $^{19}$. A esta asincronía se suma los sistemas de renovación parcial que se advierten en algunos de estos organismos que impiden bruscas renovaciones de los órganos y, por ello, de sus orientaciones (por mitades en BE, CNMV, CSN, RTVE y TDC). La consecuencia inmediata del juego de ambas características es que se producen cohabitaciones entre Gobiernos con Administraciones independientes cuyos integrantes fueron designados por otros Ejecutivos lo que, sin duda, dificulta las hipotéticas vinculaciones políticas.

18 M. MAGIDE HERRERO: Limites constitucionales de las Administraciones independientes..., pág. 107.

19 La duración en el cargo es de seis años para BE, CMT, CNE, CSN y RTVE (arts. 25 LABE, 48.7 LGT, Disp. Adic. 11.primero.4 LSH, 5.2 y Disp. Transit. 1. ${ }^{a}$ LCSN y 12.1 LRTVE) cinco años en TDC (art. 21.2 LDC) y cuatro años para APD y CNMV (arts. 36.1 LOPD y 19 y Disp. Transit. 2 LMV). 
En segundo término, en relación con las competencias personales de los candidatos, la normativa reguladora de las Administraciones independientes demanda que se nombren a profesionales de reconocida competencia, solvencia o prestigio, con cierta experiencia cuantitativa (un número de años de ejercicio) y cualitativa (desarrollo de actividades previas en los sectores que corresponda ${ }^{20}$ y recoge un elenco de causas de incompatibilidad que se han visto fuertemente reforzadas, como veremos, con la aprobación de la Ley 5/2006, de 10 de abril, de regulación de los conflictos de intereses de los miembros del Gobierno y de los Altos Cargos de la Administración General del Estado.

Por lo que se refiere a los instrumentos funcionales, la autonomía funcional de las Administraciones independientes puede deducirse, entre otros pero principalmente, del otorgamiento de competencia exclusiva sobre la materia, del carácter vinculante de sus decisiones, de su independencia respecto de órdenes e instrucciones y de la imposibilidad de revisión de sus actos. El carácter vinculante de sus decisiones se reconoce en todas las normas legales excepto en la LCSN (art. 2.2). La facultad del Ejecutivo de establecer órdenes e instrucciones como mecanismo de influencia en la Administración no se reconoce en ninguna ley reguladora de las Administraciones independientes y en aquellos casos en que se refieren expresamente a tal posibilidad es para prohibirla (art. 36.2 LOPD). En relación con la revisión de sus actos, la normativa establece que éstos agotan la vía administrativa sin posibilidad de recurso de alzada por lo que hay que acudir a la vía contencioso-administrativa ${ }^{21}$.

En lo relativo a los instrumentos financieros, las Administraciones independientes gozan de autonomía presupuestaria aunque no de máximo nivel. Esta protección total contra las influencias del Gobierno se daría si se permitiese

20 Arts. 24 LABE, 48.5 LGT, 17 LMV, 5.1 LCSN, 21.1 LDC y 14 LRTV. Destaca la inexistencia de ninguna exigencia de profesionalidad en la LOPD ya que a ninguno de los miembros del Consejo se le reclama, por tanto, tampoco al Director elegido entre ellos con la única excepción del vocal propuesto por el Consejo de Universidades. García Roca entiende que, en realidad, la mayor garantía de independencia vendrá determinada en función de la cualificación y de la profesionalidad del designado. Sus reflexiones sobre el nombramiento de los magistrados del TC resultan perfectamente trasladables a nuestro terreno: "los problemas no están pues, en las reglas, sino en su aplicación: en la necesidad de tomarse en serio por las personas que realmente seleccionan los candidatos y las aplican, dentro o fuera de los órganos que formalmente los eligen, la exigencia constitucional de ser "un jurista de reconocida competencia". Debería, seriamente, comprobarse su historial profesional en la comparecencia parlamentaria para su nombramiento para extraer de forma objetiva su comprensión personal de la jurisdicción constitucional y su actitud ante los litigios que previsiblemente deba enjuiciar. Se hace precisa en el designado la auctoritas de los romanos, alguien respetado entre sus iguales, sobre cuya personalidad pueda vertebrarse una mayoría cualificada y que por su competencia, mérito y capacidad pueda generar consenso" (J. GARCÍA ROCA: "La experiencia de veinticinco años de jurisdicción constitucional", borrador de la Ponencia General presentado al $V$ Congreso de la Asociación de Constitucionalistas de España, Valencia, 30 de noviembre y 1 de diciembre de 2006, pág. 52). Sobre la designación política de altos cargos administrativos, puede consultarse R. JIMÉNEZ ASENSIO: Altos cargos y directivos públicos. Un estudio sobre las relaciones entre política y administración en España, IVAP, Oñate, 1998, 2. ${ }^{a}$ ed.

21 Arts. 48.2 LOPD, 1.ocho LLT, 70 LCSN, 16.3 LRTV y 49 LDC. En el supuesto de BE, CNE y CNMV determinadas actuaciones son revisables ante el Ministerio de Economía (arts. 2 LABE, Disp. Ad. 11.tercero.5 LSH y 2.b LCSN). 
a las Administraciones independientes proponer directamente a las Cortes Generales su proyecto de presupuesto o aquél que previese que el envío del proyecto al Ministerio correspondiente o al Gobierno se hiciese a los solos efectos de su integración en el proyecto de Presupuestos Generales del Esta$\mathrm{do}^{22}$. Sin embargo, muchas de las leyes exigen la aprobación gubernamental del anteproyecto de presupuesto del ente ${ }^{23}$. Los ingresos de las Administraciones independientes son principalmente las asignaciones recogidas anualmente en los Presupuestos Generales del Estado y los procedentes de las tasas y, en algún supuesto, de los precios públicos por la prestación de servicios ${ }^{24}$.

Existen, por último, unos instrumentos organizativos, que se destacan como ingredientes básicos de la autonomía orgánica de las Administraciones independientes. En primer lugar, el carácter colegiado de los órganos - a excepción de la APD en la que el Director retiene las competencias ejecutivas y decisorias- puesto que se entiende que permite disolver las influencias políticas ya que, teóricamente, va a ser menos susceptible de influencia que un órgano unipersonal y, en segundo término, la autoorganización gracias a la competencia para aprobar su reglamento interno ${ }^{25}$.

En sentido totalmente opuesto a estas manifestaciones de independencia, resumimos que existen indicios en las leyes reguladoras de las Administraciones independientes que evidencian cierta influencia del Gobierno en sus actividades: el reconocimiento del derecho de asistencia de miembros del Ejecutivo en las convocatorias de los órganos de dirección; la potestad de modificación del anteproyecto de presupuestos de la entidad; la influencia sobre la materia regulada a través de la potestad reglamentaria y, sobre todo, la potestad de cesar a sus miembros cuando se produce un incumplimiento grave de obligaciones.

La conclusión que derivamos de todo ello es que, por un lado, el particular status de independencia e inamovilidad de los miembros de las Administraciones independientes y el hecho de que el Gobierno no disfrute de un mando efectivo sobre su actividad dificulta la articulación de un control parlamentario en su configuración clásica —esto es, a través del Ejecutivo—. A mayor abundamiento, las Cortes Generales intervienen en la designación de muchas de estas Administraciones imponiendo, en la práctica, que se reproduzca en esos nombramientos la representación proporcional de los partidos políticos presentes en el Parlamento. Por último, el grado de responsabilidad del Ejecutivo en muchos casos no podrá derivarse de una elección inadecuada de los miembros de los órganos directivos de las Administraciones independientes puesto que, dada la asincronía de mandatos, pueden haber sido designados por el Ejecutivo anterior.

22 Esta autonomía máxima se aprecia en los arts. 4.2 LABE, 1.3 LCSN y 34 LRTV.

23 Arts. 35.5 LOPD, 48.15 LGT, 14 LMV, Disp. Ad. 11.primero. 2 LSH.

24 Todas las Administraciones independientes se financian a través de ingresos mixtos: arts. 35.4 LOPD, 4 LABE, 48.14 LGT, Disp.Ad. 11.primero.7 LSH, 24 LMV, 9 LCSN, 32 LRTV y 20.4 LDC.

25 Art. 21.1.f) LABE, 48.10 LGT, 27 LDC y Disp. Ad. 11.tercero.16 LSH. En el caso de la APD y CSN se habilita al Gobierno para aprobar sus reglamentos (arts. 35.1 LOPF y 1.1 LCSN). 
Pero, por otro lado, es necesario reconocer la posibilidad de exigir una responsabilidad modulada al Ejecutivo por las actuaciones de los integrantes de las Administraciones independientes ya que perviven entre el Gobierno y las Administraciones independientes algunos instrumentos de relación que rebasan la mera influencia y, en todo caso, "aunque se le niegue al Gobierno la dirección de estas Administraciones no puede negarse que respecto de ellas el Gobierno tiene la responsabilidad" ${ }^{26}$.

\section{PARLAMENTARIZACIÓN DE LOS NOMBRAMIENTOS DE LOS ÓRGANOS DIRECTIVOS DE LAS ADMINISTRACIONES INDEPENDIENTES}

La atribución de la facultad de nombramiento de cargos y órganos administrativos al Congreso y al Senado o, a su nivel, a las Asambleas de las Comunidades Autónomas se consagró en el mismo momento de surgimiento de las Administraciones independientes pero se detecta, en las nuevas leyes reguladoras de estas entidades, un incremento en la tendencia de desapoderamiento al Ejecutivo de la función de nombramiento de sus integrantes y su atribución al Legislativo.

Así, a nivel estatal, la Ley de la Radio y la Televisión de titularidad estatal faculta a ambas Cámaras parlamentarias para designar a los ocho miembros del Consejo de Administración por mitades así como la designación del Presidente de la Corporación y del Consejo de Administración por el Congreso de los Diputados con una mayoría de dos tercios de la Cámara ${ }^{27}$. En el ámbito autonómico, la Ley 5/1982, de 20 de marzo, de creación Ente Público "Radio Televisión Vasca" ya contenía una previsión semejante de nombramiento parlamentario tanto de los miembros del Consejo de Administración como del Director General del Ente cuya propuesta por parte del Gobierno, debe ser aprobada con el voto favorable de, al menos, la mitad más uno de los parlamentarios (arts. 6 y 7 , respectivamente).

Asimismo, la totalidad de leyes reguladoras del Consejo Asesor de RTVE en cada Comunidad Autónoma disponen la designación parlamentaria de sus consejeros. Más recientemente podemos señalar la designación de los miembros de los Consejos Audiovisuales creados en Andalucía, Cataluña y Navarra ${ }^{28}$ : la Ley del Consejo Audiovisual de Cataluña prevé que los once consejeros

26 A. RALLO LOMBARTE: La constitucionalidad de las Administraciones independientes..., pág. 248.

27 Art. 11 de la Ley 17/2006, de 5 de junio, de la Radio y la Televisión de titularidad estatal (LRTVE).

28 La Ley 6/1999, de 1 de septiembre, del audiovisual de Galicia y el Decreto 276/1999, de 21 de octubre, que regula la composición y las funciones del Consejo Asesor de Telecomunicaciones y Audiovisual de Galicia no prevén la designación parlamentaria directa de ninguno de los miembros del Consejo. 
que componen el órgano sean de elección parlamentaria por mayoría de tres quintos y el Presidente, nombrado por el Gobierno, ha de ser propuesto por el Consejo de entre los miembros del mismo por mayoría absoluta ${ }^{29}$. En términos parecidos, la Ley del Consejo del Audiovisual de Cataluña, determina que el Consejo se integra por diez miembros: nueve de ellos son elegidos por el Parlamento, a propuesta, como mínimo, de tres grupos parlamentarios, por una mayoría de dos tercios y el Presidente es propuesto por el Gobierno después de oír la opinión mayoritaria de los nueve miembros elegidos por el Parlamento $^{30}$. Finalmente, en la composición del Consejo Audiovisual de Navarra interviene el Parlamento y el Gobierno nombrando a cinco y dos miembros respectivamente. El Presidente es elegido de entre sus miembros por mayoría de dos tercios de los mismos ${ }^{31}$.

En general, esta atribución no resulta pacífica y ha provocado una serie de objeciones. En primer lugar, se ha denunciado que la participación del órgano parlamentario en el nombramiento de los integrantes de las Administraciones independientes no resulta conciliable con el art. $97 \mathrm{CE}$ en cuanto reserva al Gobierno la dirección de la política interior y exterior y la Administración civil y militar ya que, con el nombramiento por el Legislativo, los órganos se ven hasta cierto punto alejados de la dependencia gubernamental $^{32}$. Se produciría, por tanto, una alteración del diseño constitucional de reparto de poderes al apropiarse indebidamente el Parlamento de la facultad de designar los cargos directivos de algunos de estos entes y una invasión del ámbito de reserva gubernamental. Lo cierto es que la intervención del Parlamento en la dirección de la Administración no se limita a la designación sino que puede entenderse que se produce a través de otros muchos mecanismos tales como el ejercicio de la función legislativa, del control del Gobierno o del debate presupuestario.

El Tribunal Constitucional ha tenido ocasión de pronunciarse sobre esta atribución por ley del nombramiento parlamentario de componentes de diversos órganos dando por zanjada la polémica al considerarla lícita reconociendo a las Cortes Generales una amplia capacidad de autoatribución competencial por vía legislativa ${ }^{33}$.

En segundo término, se ha puesto el acento en el riesgo de incrementar los riesgos de politización de manera que la intervención parlamentaria no la neutralizase sino que introdujese el conocido reparto por cuotas o lottizzazione en

29 Art. 5.1 y 2 de la Ley 1/2004, de 17 de diciembre, de creación del Consejo Audiovisual de Andalucía.

30 Art. 4 de la Ley 2/2000, de 4 de mayo, del Consejo del Audiovisual de Cataluña.

31 Art. 23 de la Ley Foral 18/2001, de 5 de julio, que regula la actividad audiovisual de Navarra y crea el Consejo Audiovisual de Navarra.

32 Sobre este extremo, consúltese A. RALLO LOMBARTE: La constitucionalidad de las Administraciones independientes..., págs. 171 a 177 y L. LÓPEZ GUERRA: «Modelos de legitimación parlamentaria y legitimación democrática del Gobierno: su aplicación a la Constitución española", Revista Española de Derecho Constitucional, núm. 23, 1988, págs. 81 y ss.

33 STC 108/1986, caso CGPJ, de 26 de julio, fj 12. 
las designaciones trasladando la lucha partidista al interior del organismo ${ }^{34}$. No puede dejar de reconocerse que existe este peligro de cuotificación que se apunta pero se diluye un tanto mediante la exigencia de mayorías reforzadas y que, a cambio, el nombramiento parlamentario de los integrantes de algunas Administraciones independientes aporta el beneficio superior del pluralismo, la publicidad, el debate y la necesidad de consenso.

Desde nuestro punto de vista, entendemos que, tras la atribución parlamentaria de designación de titulares de organismos autónomos, alienta la aspiración a una mayor independencia de forma que la dirección y gestión de los entes independientes responda no al interés del Gobierno, sino al del conjunto de los poderes políticos y sociales presentes en el país que se encuentran representados en el Parlamento. En realidad, la elección parlamentaria de estos cargos administrativos tiende a la representación del pluralismo, algo que en teoría es congruente con la creación de las Administraciones independientes: evitar la patrimonialización de la Administración por parte de la facción política mayoritaria. A mayor abundamiento, este objetivo de representación pluralista puede resultar más apropiado para la configuración de algunos de estos entes atendiendo al ámbito funcional en el que se proyectan sus actuaciones: funciones de garantía o defensa de algunos derechos fundamentales: el Consejo de RTVE o los Consejos Audiovisuales son, sin lugar a dudas, ejemplos paradigmáticos.

\section{LOS CONTROLES SOBRE LAS ADMINISTRACIONES INDEPENDIENTES: LAS ESPECIFICIDADES PREVISTAS EN SU CONTROL PARLAMENTARIO}

Sobre la actividad que desarrollan las Administraciones independientes se han articulado diversos tipos de control. Dejando al margen su incuestionable sometimiento al control judicial de la jurisdicción contencioso-administrativa y el control ejercido por otros órganos — como el Defensor del Pueblo ${ }^{35}$ o el control financiero del Tribunal de Cuentas- nos ocupamos del estudio de las especificidades que plantea el control parlamentario de estos entes.

34 M. SALVADOR MARTÍNEZ: Autoridades independientes..., pág. 301 y M. MAGIDE HERRERO: Limites constitucionales de las Administraciones independientes..., pág. 100.

35 El Defensor del Pueblo en cuanto supervisor de la actividad de la Administración en defensa de los derechos del Título I de la Constitución se ha referido en sus informes a las deficiencias que se detectan en el funcionamiento de algunas Administraciones independientes. Concretamente, en su Informe del año 2005, entre otras, se denuncian deficiencias en el funcionamiento y actuaciones del BE o de la CNMV (http://www.defensordelpueblo.es/index.asp?destino=informes1.asp, págs. 922 a 925$)$. 


\section{La comparecencia PREvia del Ministro competente ante las Comisiones PARLAMENTARIAS}

El primer y limitado control parlamentario que se ejerce sobre las Administraciones independientes y que cumple además una función de colaboración entre poderes ${ }^{36}$ es el que se articula como control previo: se trata de la comparecencia del Ministro competente ante la Comisión que corresponda para someterse a preguntas e interpelaciones de todas las formaciones políticas con el objeto de informar de los méritos y cualidades de la persona propuesta.

Las normas reguladoras de las Administraciones independientes han previsto la comparecencia parlamentaria del Ministro competente en los supuestos de nombramiento del Gobernador del BE; de los miembros de la CMT y de la CNE. El nombramiento de los miembros del CSN merece una atención singularizada puesto que presenta una peculiaridad frente a las anteriores designaciones: el nombramiento del Presidente y los Consejeros de este organismo es de naturaleza gubernamental pero exige una previa comunicación al Congreso de los Diputados y le dota de un derecho de veto/ratificación sobre los mencionados miembros. Por mayoría de tres quintos la Comisión competente del Congreso manifestará su aceptación o veto razonado contando con un plazo de un mes para manifestarse.

Esta comparecencia del Ministro es frecuentemente criticada ya que se entiende que en primer lugar, resulta una previsión que carece de efecto jurídico, gozando únicamente de trascendencia política ya que el posible debate que se genere en el seno de la Comisión en torno al perfil de los candidatos no puede paralizar o impedir el nombramiento y sólo tendrá el alcance político que el mencionado debate público pueda darle y, en segundo término, al impedirse la presencia directa de los propuestos ante la Comisión parlamentaria, se debilita la legitimación política del nombramiento ${ }^{37}$. Además se ha querido advertir en este tipo de procedimientos un proceso de "presidencialización" del parlamentarismo al tratarse de un mecanismo de control típicamente presidencialista,

36 J. A. SANTAMARÍA PASTOR: "La actividad del Gobierno y de la Administración Pública como objeto del control parlamentario", en VI Jornadas de Derecho Parlamentario. Problemas actuales del control parlamentario. Enero 1995, Congreso de los Diputados, Madrid, 1997, pág. 472.

37 Muy crítico con la patrimonialización de los nombramientos de los más altos cargos de la Administración por parte de los partidos - especialmente, del que cuenta con la mayoría gubernamental — se ha manifestado Blanco Valdés quien denuncia que esta patrimonialización comporta disfunciones y consecuencias indeseadas que "no se reducen solamente a las directa o indirectamente emparentadas con la corrupción, sino que han tenido también, otras perturbadoras traducciones: entre ellas, que los gobiernos han nombrado altos cargos con independencia de la capacidad técnica, preparación profesional o adecuación personal de los candidatos al puesto para el que eran designados; que se han nombrado militantes o dirigentes de partidos incluso en puestos que, por su propia naturaleza, exigían ser cubiertos por personas con un perfil de cierta independencia $\mathrm{o}$, si se prefiere, de cierta neutralidad política; y, por último, que se han decidido los nombramientos al margen, en no pocos casos, de la existencia de datos biográficos que indiscutiblemente los desaconsejaban" (R. L. BLANCO VALDÉS: "El botín de los colonizadores", en Las conexiones políticas. Partidos, Estado y sociedad, Alianza Editorial, Madrid, 1998, pág. 142). 
esto es, desprovisto de un componente sancionador inmediato, por cuanto deferido al cuerpo electoral ${ }^{38}$. No se discute la limitada virtualidad de este instrumento como mecanismo de control de la decisión gubernamental pero, a la hora de calibrar las hipotéticas ventajas que puede reportar, debemos centrarnos en un concepto amplio del control parlamentario entendiéndolo "como una actividad de verificación e influencia distinta a la de la exigencia de la responsabilidad política del gobierno y susceptible de generar consecuencias diversas, entre las que se cuenta - pero no únicamente- la ruptura de confianza que liga al Parlamento con el Gobierno" 39 señalándose que el Legislativo, a través de una multiplicidad de actos, examina y controla el funcionamiento del Ejecutivo y de la Administración pública, e informa sobre ello al pueblo, a la opinión pública, a los medios de comunicación y al cuerpo electoral manteniendo, pues, un concepto de control que conecta con los ciudadanos y cuya sanción se encuentra en una "responsabilidad difusa" ${ }^{40}$. Se trata de un entendimiento diferente de la función de control que rompe con el binomio control/sanción (inmediata) y dota de mayor protagonismo al componente informativo y formativo de la opinión pública ${ }^{41}$. Esta función se cumple, ciertamente, con la publicidad y el debate que se articula en torno a las comparecencias parlamentarias.

38 J. L. REQUEJO PAGÉS: “Las relaciones entre el Gobierno y las Cortes Generales", Revista Española de Derecho Constitucional, núm. 70, 2004, pág. 86. Se trataría, efectivamente, de la importación de los hearings senatoriales que, en el sistema presidencial norteamericano, actúan como verdaderos mecanismos de control (check and balances) del poder presidencial al exigir el consentimiento del Senado para los nombramientos de todos los cargos públicos.

39 J. GARCÍA MORILLO: El control parlamentario del Gobierno en el ordenamiento español, Congreso de los Diputados, Madrid, 1985, pág. 119. Sobre la controversia acerca del concepto de control - la consideración o no como tales de todos aquellos instrumentos que implican una fiscalización de la actuación del Gobierno pero que carecen de la nota sancionatoria en el plano jurídico- puede verse, J. R. MONTERO y J. GARCÍA MORILLO: El control parlamentario, Tecnos, Madrid, 1984; L. LÓPEZ GUERRA: "La función de control de los Parlamentos. Problemas actuales", en El Parlamento y sus transformaciones actuales, Tecnos, Madrid, 1990, págs. 233 a 246; M. ARAGÓN REYES: “El control parlamentario como control político", Revista de Derecho Político, núm. 23, 1986, págs. 9 a 39; F. RUBIO LLORENTE: "El control parlamentario", en La forma del poder. Estudios sobre la Constitución, CEC, Madrid, 1997, págs. 241 a 258; F. SANTAOLALLA LÓPEZ: "La función de control y la ciencia del Derecho Constitucional", Revista de las Cortes Generales, núm. 12, 1987, págs. 219 a 241; J. F LÓPEZ AGUILAR: Minoría y oposición en el parlamentarismo. Una aproximación comparativa, Congreso de los Diputados, Madrid, 1991, págs. 270 a 279 y R. GARCÍA MAHAMUT: Las Comisiones Parlamentarias de Investigación en el Derecho Constitucional español, McGraw-Hill, Madrid, 1996, págs. 150 a 159.

40 Se trataría de la noción que ha formulado Giuseppe Ugo Rescigno para quien, al lado de una responsabilidad política institucional, existe otra de naturaleza difusa caracterizada por la existencia de mecanismos institucionales que, a partir de la libertad crítica de los ciudadanos, transforman los equilibrios políticos y pueden determinar incluso la remoción extraparlamentaria de los gobernantes (G. U. RESCIGNO: La responsabilità politica, Giuffrè, Milán, 1967, págs. 113 a 130).

41 De manera que "no tiene hoy ningún sentido atribuir al Parlamento la función de garantizar el sometimiento del Gobierno a la voluntad mayoritaria del último electorado, sino justamente la de asegurar la posibilidad del cambio de esa misma voluntad" (J. L. REQUEJO PAGÉS, "Las relaciones entre el Gobierno y las Cortes Generales”, ..., pág. 87). 
2. El CONTROl PARLAMENTARIO DE CONFLICTOS DE INTERESES: LA LEY 5/2006, DE 10 DE ABRIL, DE REGULACIÓN DE LOS CONFLICTOS DE INTERESES De los miembros del Gobierno y de los Altos Cargos de la ADMINISTRACIÓN GENERAL DEL EsTADO

La reciente aprobación de la Ley 5/2006, de 10 de abril, de regulación de los conflictos de intereses de los miembros del Gobierno y de los Altos Cargos de la Administración General del Estado ${ }^{42}$ ha introducido un novedoso instrumento de control sobre los miembros que integran las Administraciones independientes y supone, sin lugar a dudas, un avance en cuanto al control democrático en la designación de estos cargos al prever su comparecencia directa ante órganos parlamentarios.

El objetivo de la Ley, como reza su Preámbulo, es el de introducir exigencias y cautelas que garanticen que no se van a producir situaciones que pongan en riesgo la objetividad, imparcialidad e independencia del alto cargo. Por ello, entre otros requisitos, se exige que el Gobierno, con carácter previo al nombramiento de las personas que vayan a ser designadas máximos responsables en determinados organismos, ponga en conocimiento del Congreso de los Diputados el nombre de la persona propuesta para el cargo a fin de que pueda disponer su comparecencia ante la comisión correspondiente de la Cámara (art. 2.2 de la Ley). La comisión parlamentaria del Congreso de los Diputados examinará, en su caso, a los candidatos propuestos y sus miembros formularán las preguntas o solicitarán las aclaraciones que crean convenientes emitiendo un dictamen en el que se establecerá si se aprecia o no la existencia de conflicto de intereses (art. 2.3 de la Ley).

Por lo que a nosotros nos interesa, el ámbito de aplicación de esta norma incluye al Presidente y vocales del TDC; al Director de la APD; al Director general del Ente Público RTVE; al Presidente y vocales de la CNMV; de la CMT; de la CNE; al Presidente, los consejeros y el Secretario General del CSN; al Gobernador, Subgobernador y miembros del Consejo de Gobierno del BE así como el Presidente y los miembros de los órganos rectores de cualquier otro organismo regulador y de supervisión (arts. 2.2, 3.2 y Disp. Adic. Segunda de la Ley).

La Ley establece un régimen de prevención de situaciones de conflictos de intereses de los miembros del Gobierno y de los altos cargos de la Administración del Estado, entre otros, consagrando el principio de dedicación exclusiva a su puesto público, reforzando el control sobre los intereses patrimoniales o introduciendo un control adicional en el desempeño de actividades privadas de los altos cargos cuando cesan en sus puestos. El órgano competente para la gestión del régimen de incompatibilidades de altos cargos es la Oficina de Conflictos de Intereses (art. 15 de la Ley) y, para asegurar la transparencia del

$42 B O E$, núm. 86, de 11 de abril de 2006. Esta norma deroga la Ley 12/1995, de 11 de mayo, de incompatibilidades de los miembros del Gobierno de la Nación y de los altos cargos de la Administración General del Estado. 
control del régimen de incompatibilidades previsto en la norma, este órgano elevará al Gobierno cada seis meses, para su remisión al Congreso de los Diputados, información detallada del cumplimiento de los altos cargos de las obligaciones de declarar así como de las infracciones que se hayan cometido y de las sanciones impuestas, e identificará a sus responsables (art. 16 de la Ley). Por último, señalar que el órgano competente para ordenar la incoación del procedimiento sancionador en el supuesto de los miembros de Administraciones independientes es el Ministro de Administraciones Públicas (art. 21 de la Ley). La sanción prevista por infracción muy grave comprenderá, en todo caso, la destitución en los cargos que ocupen y la prohibición de ser nombradas para ocupar ninguno de los cargos a los que se aplica la Ley durante un período de entre 5 y 10 años (art. 18 de la Ley).

Las ventajas que reporta esta normativa nos parecen obvias: no sólo se intensifica el debilitado control parlamentario que, hasta ahora, se ejerce sobre las entidades independientes sino que, además, se está tratando de evitar el llamado riesgo de captura de este tipo de Administraciones por los sectores regulados por el organismo. El control de la posible confluencia de intereses públicos y privados propios de los altos cargos no hace sino reforzar la independencia efectiva de estos últimos. Se trata, en última instancia, de un mecanismo de preservación de la autonomía en el proceso de la toma de decisiones reguladoras.

Entendemos que la comparecencia parlamentaria del Ministro competente para informar de su propuesta de nombramiento ante la Comisión que corresponda y la comparecencia directa de los candidatos para verificar la compatibilidad de intereses son absolutamente conjugables ya que recaen sobre diferentes sujetos (Ministro y candidato) y sobre objetos distintos (examen del perfil profesional del propuesto y control de intereses). Esta compatibilidad parece confirmarse cuando analizamos el proyecto de ley de Defensa de la Competencia que, actualmente, se encuentra en tramitación ante el Congreso de los Diputados ${ }^{43}$. El proyecto de ley crea en el ámbito estatal una institución única e independiente del Gobierno, la Comisión Nacional de la Competencia, que integrará a los actuales Servicio y Tribunal de Defensa de la Competencia que desaparecen y será el órgano encargado de promover y proteger el mantenimiento de una competencia efectiva en todos los sectores productivos y en todo el territorio nacional. A los efectos que nos ocupan, se dispone que el Presidente y los consejeros sean nombrados por el Gobierno a propuesta del Ministro de Economía y Hacienda entre juristas, economistas y otros profesionales de reconocido prestigio, previa comparecencia ante la Comisión de Economía y Hacienda del Congreso, que versará sobre la capacidad y conocimientos técnicos de los candidatos propuestos (art. 29.1 y 2 del proyecto).Y en el precepto relativo a las incompatibilidades, se prevé la aplicación de la Ley 5/2006, de 11 de abril, de regulación de los conflictos de intereses de los miembros del 
Gobierno y de los Altos Cargos de la Administración General del Estado de control (art. 31 del proyecto) lo que implica la comparecencia parlamentaria previa a su nombramiento de todos los miembros de la Comisión y, como indicábamos, la compatibilidad de ambas comparecencias.

\section{Otros MECANismos DE CONTROL PARLAMENTARIO}

El ordenamiento español ha previsto otros mecanismos de control parlamentario sobre las Administraciones independientes. Advertimos una especie de "compensación" moderada de los mecanismos de control en torno a las Administraciones independientes de modo que el bloqueo de la dirección gubernativa sobre estos organismos se trata de equilibrar con una mayor supervisión de las actividades de las Administraciones independientes en la institución parlamentaria aunque se trata, sin lugar a dudas, de una modalidad de control ciertamente debilitada ${ }^{44}$.

Algunos de estos mecanismos de control que se dirigen directamente sobre las autoridades independientes son los que habitualmente se emplean para encauzar el control del Ejecutivo en sede parlamentaria (preguntas, interpelaciones y comparecencias ante Comisiones) mientras que otros son específicos para supervisar la actuación de estas entidades autónomas (envío de informes anuales o periódicos de su actividad - art. 11 LCSN, art. 13 LMV, art. 10.2 LABE, art. 26 LDC, art. 48.11 LGT, art. 39 LRTV - o creación de Comisiones especializadas en la supervisión de las Administraciones independientes - Comisión de control parlamentario de RTVE).

A pesar de que la ley desapodera al Ejecutivo de ejercer una función directiva sobre las Administraciones independientes, en la práctica, se ha admitido que el control sobre las Administraciones independientes se realice directamente sobre el Gobierno contando con el beneplácito tanto del Ejecutivo como de los entes autónomos. En estos supuestos de ejercicio del control parlamentario directo sobre el Gobierno siempre se deben tener en cuenta las limitaciones o modulaciones de responsabilidad a las que nos hemos venido refiriendo. En primer lugar y en buena lógica, el Gobierno sólo debería responder de lo que controla es decir, del incumplimiento grave de obligaciones y de los casos concretos en los que se le atribuye control sobre determinadas actividades. Por ello, el Legislativo podría exigir responsabilidades al Ejecutivo por un funcionamiento gravemente dañoso de este tipo de autoridades. El funcionamiento ordinario o diario debe quedar preservado de este tipo de control político so pena de socavar la independencia de las entidades autónomas. En segundo término, dada la inexistencia en nuestro ordenamiento jurídico de

44 Esta tendencia a fomentar el control de las agencias independientes en el Parlamento también se advierte en Europa. Sobre este tema, puede verse E. VÍRGALA FORURÍA: "Agencias (y Agencias reguladoras) en la Comunidad Europea", Revista de Derecho Constitucional Europeo, núm. 5, 2006, págs. 145 a 212. 
ningún mecanismo de moción de censura individual de miembros del Ejecutivo, la máxima sanción que podría derivarse - al margen de la ya comentada responsabilidad difusa - sería la de aprobar una moción de reprobación individual contra el cargo ministerial por incumplimiento de su deber de vigilan$\mathrm{cia}^{45}$.

Como vimos, esta imputación de responsabilidad al Ministro competente por las funciones y actividades que desarrollan las Administraciones independientes, está directamente vinculada con la facultad de cese o remoción que las normas reguladoras de aquellos entes le reconocen y rompen con la idea de la inamovilidad de los órganos directivos de las Administraciones independientes como garantía absoluta. Con idéntico objetivo de eliminar la existencia de ámbitos públicos exentos de control, cuando el órgano designante es el Parlamento, las normas reguladoras contemplan un mecanismo de remoción para el que se exigen mayorías cualificadas idénticas a las determinadas para el nombramiento [por ejemplo, art. 13.1.d) LRTVE].

Estas previsiones no sólo nos parecen apropiadas para garantizar la viabilidad de la responsabilidad política gubernamental y el ejercicio del control parlamentario de las Administraciones independientes sino que entendemos que no comportan ningún riesgo añadido sobre el status de independencia que se predica de los miembros de estos organismos y sirven perfectamente al objetivo de evitar al máximo que se quiebre esa relación bilateral que hay habitualmente en Derecho entre competencia y responsabilidad.

ABSTRACT. In the democratic State, under the rule of law, the existence of spheres free from direct or indirect parliamentary control is inconceivable. Under the administrative management clause of art. 97 EC, discretionality or administrative opportunity is subject to political control, in that it is the Government which takes responsibility for it before Parliament and public opinion. However, the appearance in Spain more than two decades ago of spheres of public affairs management characterised by their neutrality and provided with independent status with respect to governmental power has broken down this classic circuit of responsibility. This study analyses the specific features shown by the Parliamentary control mechanisms to which the actions of Independent Agencies are subject in the Spanish legal system.

45 Sobre este instrumento de control, véase J. GARCÍA ROCA: "La fragilidad de los Ministros (de su competencia y responsabilidad directas)", Cuadernos de Derecho Público, núm. 18, 2003, págs. 55 a 97, especialmente, págs. 87 a 94. 